\title{
EXPERIMENTAL STUDY OF TACTICAL AND TECHNICAL CHARACTERISTICS OF THE ELECTRIC DRIVE OF A STRIKEBALL WEAPON
}

\author{
BEREZHANSKY O. A., Pskov State University, \\ Department of Computer Science and Electric Power Engineering \\ 2nd year, bachelor's degree \\ (Research Supervisor - Associate Professor Markov A.M.)
}

Electro-pneumatic actuator is an accurate external modulation of combat weapons, which is used for tactical games and development of combat skills. Electro-pneumatic drive (AEG) and its advantage in high speed of fire were investigated in the experiment and the number of its shots exceeds even the number of combat weapon's shots. The other advantages are the large number of shots on a standard battery and miniature design, because weight and size are more modulation requirement than necessity

For the experiment, we took the CYMA drive, model CM045.

This model is equipped with a LiPo type battery, voltage $11.4 \mathrm{~V}$ and a capacity of $1400 \mathrm{mAh}$. According to the stated characteristics: ball speed is $(0.2 \mathrm{gram}) 120 \mathrm{~m} / \mathrm{sec}$. Shot rate is 750 shots per minute.

The appearance of the experimental stand is shown in the picture 1.

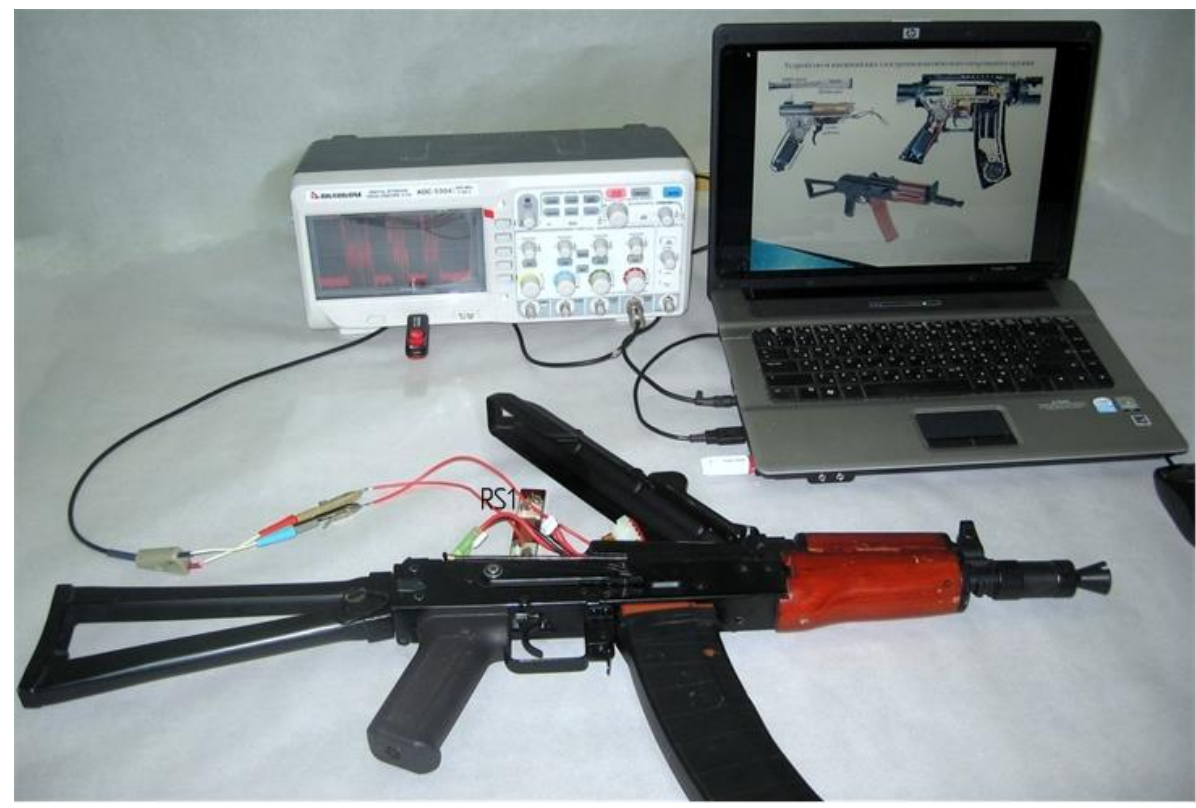

Scheme. 1. Appearance of the experimental stand

The schemes of electric principle Electro-pneumatic actuator have been developed for the purpose of experimental research of tactical and technical characteristics of a Electro-pneumatic actuator. They are shown in the pic. 2-a, b.

The diagrams are designed to control the M1 engine of a Electro-pneumatic actuator, which converts the electrical energy of the GB1 battery into mechanical (pneumatic) energy transmitted to the ball in order to move it in space at a speed of 120-130 m/s. In addition, the schemes contain elements that protect the components in emergency situations: short-circuits and overload currents. 

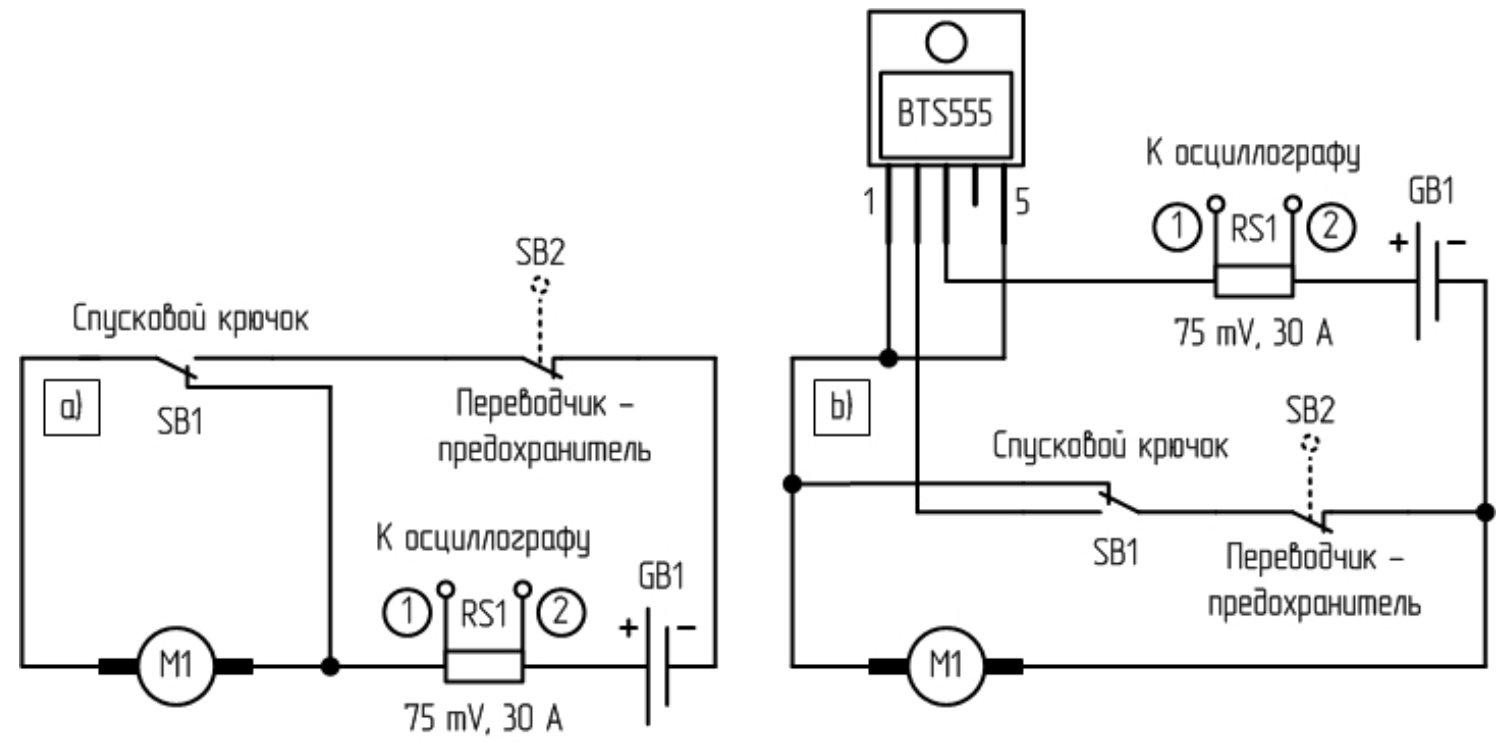

Scheme. 2. Electrical circuit diagram of the main thrust actuator ( $a$ - typical inclusion scheme; $b$ - modernized scheme)

In the typical scheme (Fig. 2-a), the motor control of M1 is carried out with the help of the button SB1 ("Trigger"), through which the power current of the electric motor M1 flows. The firing rate (automatic semi-automatic rifle) is set by the SB2 switch ("Translator - fuse").

The modernized control system (Fig. 2-b) is based on the intelligent electronic key BTS555, the power part of which is represented by an IGBT-transistor with low resistance in a fully open state. The electronic key includes elements of protection against exceeding the permissible temperature of the semiconductor crystal, as well as protection against polarity reversal and excessive currents. This technical solution eliminates the flow of power currents through the mechanical contacts of the trigger button SB1. When the M1 is switched off, dynamic braking is used.

A Commander-GP1000 type DC motor [1, p. 60-100] is used as a drive motor with the following specifications: $\mathrm{Un}=11 \mathrm{~V}, \mathrm{In}=20 \mathrm{~A}, \mathrm{Pr}=3000 \mathrm{rpm}$. The circuit is powered by a $1400 \mathrm{mAh}$ battery with a voltage of $11.4 \mathrm{~V}$.

The inductive electric shunt RS1 $75 \mathrm{mV}, 30 \mathrm{~A}$. is installed in the circuit to measure the current and remove the oscillograms.

Voltage (current) oscillograms in the control points of the circuit (see Fig. 2) at various initial parameters of control of the trike-ball drive are shown in Fig. 3.

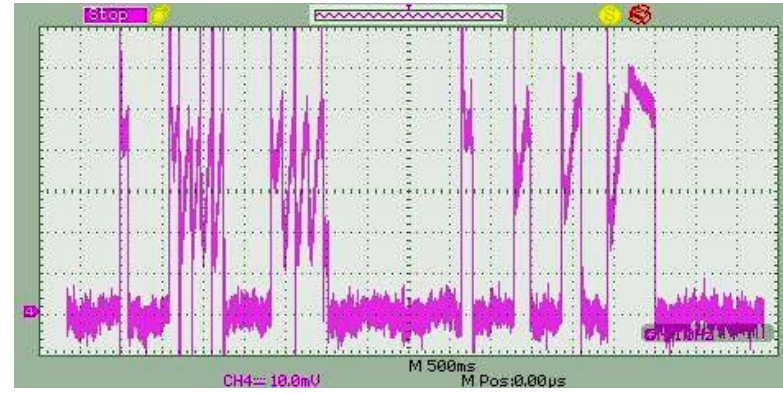

a)

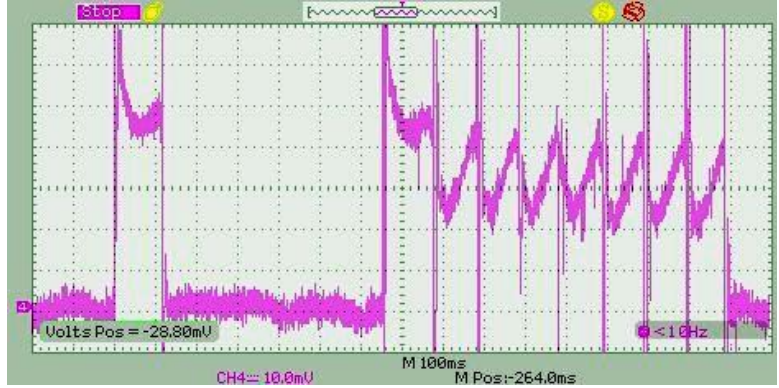

б)

Scheme. 3. Oscillograms in the control points of the circuit: a - semi-automatic firing; $b$ - automatic firing.

On the chart. 4. The graphs of experimental studies, which represent the dependence of the firing range on the angle of elevation of the $\alpha$-barrel of the striker rifle, are presented on the pic. 4 


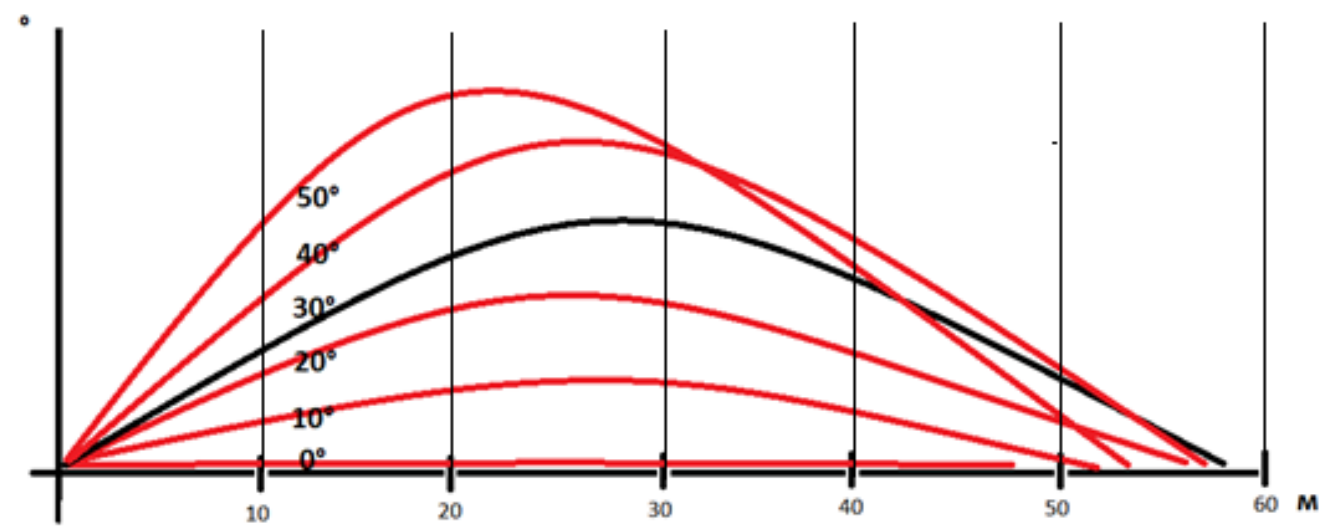

\begin{tabular}{|c|c|c|c|c|c|c|}
\hline Angle, $\left(0^{\circ}\right)$ & $0^{\circ}$ & $10^{\circ}$ & $20^{\circ}$ & $30^{\circ}$ & $40^{\circ}$ & $50^{\circ}$ \\
\hline Max. Range, (м) & 47 & 52 & 56 & 58 & 57 & 54 \\
\hline
\end{tabular}

\section{Conclusions}

During the period of the scientific work on the abovementioned topics the following tasks were considered and solved:

1. The relevance of theoretical study and practical application of strikeshot weapons with "soft pneumatics" has been proved.

2. The scheme of electric principal Electro-pneumatic actuator with intelligent electronic keyswitch has been developed.

3. A wide range of experimental studies with the application of a full-scale object - a CYMA CM045 Electro-pneumatic actuator machine - has been performed.

\section{Literature}

1. Markov A.M. Electrical machines and micromachines. Ch. V. Pskov, 2015. 